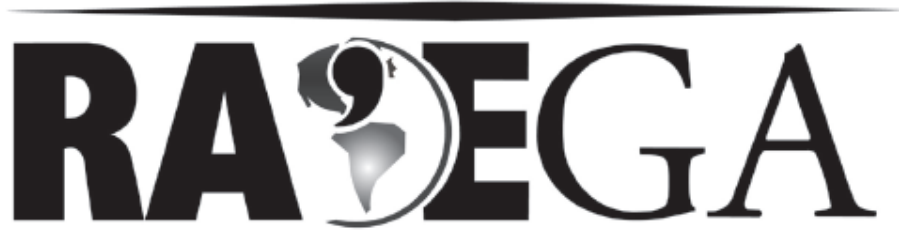

O ESPAÇO GEOGRÁFICO EM ANÁLISE

\title{
A GEOGRAFIA GERAL (1650) DE BERNHARDUS VARENIUS: A MODERNIDADE DA OBRA
}

\section{THE BERNHARDUS VARENIUS GENERAL GEOGRAPHY (1650): THE MODERNITY OF THE WORK}

\author{
Fabrício Pedroso BAUAB ${ }^{1}$
}

\section{RESUMO}

O presente artigo realiza um resgate da obra Geografia Geral (1650) de Varenius (1621/1622-1650), procurando nela identificar elementos que caracterizaram o pensamento e a ciência ocidentais no início da modernidade. A filiação ao heliocentrismo copernicano, a adoção de princípios do cartesianismo, a atualização da imagem de mundo com base nas informações dos chamados Descobrimentos Marítimos e a total isenção da Geografia frente ao temário religioso constituem alguns dos elementos modernos presentes no texto do geógrafo alemão.

PALAVRAS-CHAVE: Geografia; Ciência Moderna; Descobrimentos; Modernidade.

\section{ABSTRACT}

The current article accomplishes a capitulation of the General Geography(1650) of Varenius (1621/1622-1650), seeking in it elements that characterizes the occidental thought and science in the beginning of modernity. The filiation to the Copernican heliocentrism, the adoption of Cartesianism principles, the updating of the world image based on the information called Maritime Discoveries and total exemption of Geography towards the religious reckless constitute some of the modern elements in the text of the German Geographer.

KEY WORDS: Geography; Modern Science; Discoveries; Modernity.

\footnotetext{
${ }^{1}$ Mestre e Doutor em Geografia pela Universidade Estadual Paulista (UNESP), campus de Presidente Prudente. Professor Adjunto do Curso de Geografia da Unioeste (Universidade Estadual do Oeste do Paraná), campus de Francisco Beltrão.E-mail: fabriciobauab@yahoo.com.br
} 


\section{Introdução}

A figura da Bernhard Varenio, Bernard Varen ou Bernhardus Varenius, na versão latinizada do nome, não é muito conhecida na história do pensamento geográfico. Pelo menos não, em nosso entendimento, na sua devida importância.

Alusões positivas a ele aparecem, por exemplo, em Hartshorne (1978), que ressalta o fato de Varenius ter se preocupado com a articulação entre postulados gerais do conhecimento geográfico e sua relação com particularidades regionais (Geografia Especial). Schaefer (1976), por sua vez, em seu clássico texto que contém aspectos precursores e talvez normativos do que veio a se chamar de Geografia Pragmática, ou Nova Geografia, criticando a posição "excepcional" atribuída ao conhecimento geográfico por Kant, escreveu: Kant era um geógrafo de poucos méritos em comparação com os seus contemporâneos ou mesmo Bernhard Varenius, que faleceu mais de cento e cinqüenta anos antes dele (1976, p.18).

Num período mais recente, o estudo de Warntz $(1989)^{2}$, que pautará parte das informações de que lançaremos mão neste artigo, resgata a importância histórica do geógrafo alemão. Warntz se referenciou, para expor o teor moderno do texto de Varenius, em autores como Lange (1961) ${ }^{3}$ e Lebed'ev (1950) ${ }^{4}$. Nestes trabalhos, o que se procura evidenciar, portanto, é o aspecto moderno da obra máxima de Varenius, a Geografia Geral, publicada originalmente em 1650. É neste sentido que Capel (1984), em extenso e valioso estudo que precede a edição espanhola de parte do texto de 1650 que estaremos usando aqui, ressalta ser Varenius um claro precursor da Geografia Moderna.

Nosso artigo pretende, neste cenário, contribuir para a compreensão do ineditismo em termos de método e conteúdo presente no texto de Varenius. Podemos de antemão afirmar que a aplicabilidade de preceitos cartesianos à Geografia, como a predileção pela matemática como sistema organizacional

\footnotetext{
${ }^{3}$ LANGE, Gottfired. Das Werk dês Varenius. Erdkunde 15 (1): 1-18. 1961.

${ }^{4}$ LEBEDEV, D.M. Geografia v. Rossie Petrovskogo> Moskva: Akad. Nauk, 1950.
} 
apriorístico do conhecimento, a adoção inédita do heliocentrismo numa obra geográfica, a completa separação da Geografia de premissas religiosas e o diálogo crítico com as mais novas informações oriundas dos Descobrimentos Marítimos, tornam a Geografia Geral um texto fundamental no processo histórico de construção de um conhecimento geográfico de feições modernas.

\section{Vida e obra}

Varenius nasceu em Hitzacker, Alemanha, entre 1621 e 1622. Devido à Guerra dos Trinta Anos, entretanto, como ressalta Warntz (1989), teve que se mudar para Amsterdã, uma vez que a sua família era de origem protestante. $\mathrm{Na}$ Epístola que abre a Geografia Geral, Varenius faz alusão à redução de sua cidade a chamas por ocasião da referida guerra. Elogiando Amsterdã, escreveu:

\footnotetext{
Pues cuando mi pátria, agotada por diversas desgracias de la guerra pasada, fue finalmente reducida a llamas y cenizas me dirigi por cierto hado bueno o más bien la providencia excelentíssima y amplíssima de Dios, a vuestra ciudad, donde encontre una oportunidad favorable para escribir sobre temas que no hubiera podido realizar de residir en otro lugar (VARENIO, 1984, p.93-94).
}

Antes de ir para a Holanda, entretanto, estudou Medicina em Hamburgo entre 1640 e 1642, e na Universidade de Königsberg, em 1645. Em relação à Königsberg, Varenius, de acordo com Warntz (1989), teria ficado decepcionado com o conservadorismo imperante no seu meio acadêmico.

Capel (1984) destaca que Amsterdã, cidade que desempenhou um papel decisivo na vida de Varenius, era, no século XVII, um verdadeiro empório comercial, além de um ativo centro de navegação mundial. Além disso, teria se transformado, em meados deste século, no principal centro cartográfico europeu, publicando várias edições da obra de Mercator.

Teria sido na Holanda, mais especificamente na Universidade de Leiden, que Varenius foi despertado para o conhecimento científico, num âmbito geral, e pela Matemática, num âmbito mais específico. 
Leiden era na época, segundo Capel (1984), um dos principais centros de produção de conhecimento matemático da Europa, além de ser um reduto do cartesianismo. Foi em Leiden que Varenius obteve sua formação acadêmica em Medicina. Para tanto defendeu a tese intitulada Disputatio Medica Inauguralis, De Febri in Genere, no ano de 1649.

Ainda em 1649 Varenius publicou um primeiro esboço de aplicação de sua proposta de uma Geografia Regional ou Especial. Este primeiro esboço, um estudo específico sobre o Japão, recebeu o título de Descriptio Regni Japoniae, e compôs uma compilação de textos sobre o Extremo Oriente chamada Descriptio Regni Japoniae cum quibusdam affinis materiae (1649).

Warntz (1989) ressalta que o referido estudo teria sido dedicado à rainha Christine da Suécia, talvez expressando uma intenção de ingresso na sua corte. Nas primeiras 210 páginas do texto de $1649^{5}$, Varenius apresentou informações como: a localização, a extensão, divisão e primeiras notícias que tiveram os europeus deste reino; características do país como água, montes, plantas e animais; a origem dos seus habitantes; o governo; matrimônio, educação, penas e castigos; questões militares; artes; alimentos; comércio, entre outros aspectos.

Outros escritos de Varenius são: Tabulae Historae Universalis (Amsterdã, 1649); seu ensaio acadêmico intitulado De Definitione Motus Aristotelica (1642); De Lineis Curvis, Imprimis Sectionibus Conicis (1648). Esta última obra concedeu a Varenius o título de Professor de Ciências da Natureza.

Foi, contudo, a Geographia Generalis (Geografia Geral, em que se explicam as propriedades gerais da Terra, originalmente contendo 786 páginas), publicada em Amsterdã no ano de 1650, a obra de maior relevância de Varenius.

A repercussão da Geografia Geral foi, com certeza, amplificada pelo apreço nutrido por ela por Sir Isaac Newton. O eminente físico inglês, mesmo se deparando no texto com a presença de vários elementos da física

\footnotetext{
${ }^{5}$ Capel (1984) salienta que o texto de Varenius de 1649 explicita o vinculo privilegiado que a Holanda tinha com alguns reinos do Extremo Oriente no séc. XVII, especialmente o do Japão. Em de 1630, Capel (1984) destaca que o governo japonês havia proibido a atividade de jesuítas portugueses em seu reino. Assim, a partir de 1641 , os holandeses começaram a substituir os portugueses no intercâmbio com o Japão. Cabe salientar que as informações contidas no Descriptio Regni Japoniae são oriundas de estudos realizados pelos jesuítas e, também, do intercâmbio holandês estabelecido com o Japão.
} 
cartesiana dos turbilhões, rejeitada por ele, organizou duas edições dela, uma de 1672 e outra de 1681. Em 1712, James Jurin, Roger Cotes e Edmund Halley, todos nomes ligados a Newton, organizaram uma nova versão, atualizada pelos feitos da física newtoniana (WARNTZ, 1989). Data de 1715 a primeira edição italiana, publicada em Nápoles. Cabe ressaltar que após 1750, surgiram traduções para o holandês, para o francês e inglês. Ainda em 1718 apareceu uma primeira versão russa para a Geografia Geral, baseada na primeira edição de Newton. Tal edição serviu de livro texto para oficiais da marinha.

Na Espanha houve um total desconhecimento da obra nos séculos XVII e XVIII. Capel (1984) ressalta que tal hiato se deu motivado pela resistência à origem holandesa e protestante do texto.

Presume-se que 1650 seja o ano de morte de Varenius, pois a última informação sobre ele data de agosto do aludido ano.

\section{O contexto: o surgimento da Ciência Moderna e os Descobrimentos Marítimos}

O cenário histórico existente à época de Varenius teve por característica, conforme já pudemos observar na breve descrição que fizemos da vida e obra do autor, a eclosão de uma série de eventos que podem ser considerados extremamente importantes para a irrupção da modernidade: a eclosão da Reforma Protestante e a cisão inédita inserida por ela na Cristandade; o surgimento e a consolidação dos Estados Nacionais; a gênese da Ciência Moderna com a contribuição de autores como Johannes Kepler e Galileu Galilei; a aproximação da filosofia com as problemáticas ensejadas pela ciência nascente através das obras de F. Bacon e Descartes; o mercantilismo estimulado, em parte, pelas conquistas ultramar dos chamados Descobrimentos Marítimos.

É, portanto, dentro deste cenário efervescente em acontecimentos e desdobramentos, que devemos situar a Geografia Geral de Varenius. Como a complexidade e enredamento destes eventos escapam às possibilidades deste artigo, trataremos, na seqüência, de dois temas que podem ser identificados de 
forma mais próxima no clássico texto do autor. Assim, antes de entrarmos especificamente no texto de 1650, abordaremos, ainda que sucintamente, o surgimento da Ciência Moderna e os chamados Descobrimentos Marítimos.

\subsection{A Ciência Moderna}

Pode ser afirmado que Varenius teve acesso aos desdobramentos da chamada Revolução Científica do séc. XVII, dialogando, como veremos na sequência do presente texto, com vários dos temas abordados por ela.

A partir de Nicolau Copérnico (1473-1543), a posição privilegiada do homem no cenário geral da Criação sofreu um imenso abalo, uma vez que o heliocentrismo sugerido pelo monge polonês opôs à visão tradicional de mundo uma imagem de cosmo radicalmente diferente daquela proveniente do geocentrismo aristotélico-ptolemaico, convenientemente incorporado à síntese cristã. Assim, em seu De revolutionibus orbium coelestium, Copérnico anunciou seu heliocentrismo numa bela e conhecida passagem: (...) quem haveria de colocar neste templo, belo entre os mais belos, um tal luzeiro em qualquer outro lugar melhor do que aquele donde ele pode alumiar todas as coisas ao mesmo tempo? (1991, p.53).

Outro golpe radical na imagem tradicional de universo foi desferido por Giordano Bruno (1548-1600) que em seu diálogo intitulado Sobre o infinito, o universo e os mundos equiparou Criador e Criação ao estender o atributo da infinitude às coisas criadas por Deus. A ousadia do pensador italiano se manifestou, portanto, em uma concepção panteísta de mundo, que em última instância rompeu com a distinção entre o natural e o sobrenatural, unificandoos em uma mesma realidade. Sobre a tradicional visão de cosmo - e de mundo - Giordano Bruno escreveu: A bela ordem e hierarquia da natureza é um gracejo ingênuo e um gracejo de velhas decrépitas (p.15). Os "decrépitos" representantes da velha ordem o queimaram vivo em $1600 \ldots$

Johannes Kepler (1571-1630) negou a infinitude do universo sugerida pela prosa poética e filosófica de Giordano Bruno. Tal aspecto, entretanto, não o aproximou do saber venerável e tradicional. Pelo contrário. O que o incomodava em Giordano Bruno era, entre outros aspectos, o tom altamente 
especulativo dos seus argumentos. Assim, sua contribuição à ciência, ainda tributária de um forte misticismo pitagórico, se deu na defesa do caráter independente do saber científico, que deve ser pautado em rígidos critérios de experiência e fundamentado, em última instância, em demonstrações matemáticas, uma vez que, para ele, nada pode ser conhecido completamente, exceto as quantidades, ou por meio de quantidades e, por essa razão, as conclusões da matemática são mais certas e indubitáveis (KEPLER apud BURTT, 1991, p.52).

A paixão ardente pelos fatos empíricos, traço tipicamente moderno, Kepler buscou, de acordo com Burtt (1991), em Tycho Brahe (1546-1601). As tabelas de cálculos acerca dos movimentos dos planetas geradas pelo astrônomo dinamarquês foram fundamentais para que Kepler também redimensionasse nossa visão de mundo ao provar o caráter elíptico das órbitas planetárias, fugindo assim, do primado dos movimentos circulares.

Galileu Galilei (1564-1642), em O ensaiador, explicitou a deferência à matemática que os, digamos, construtores da Ciência Moderna, possuíam. Tentando enfatizar a alteridade da natureza diante dos aspectos subjetivos do sujeito, tratou de caracterizá-la enquanto repositório de elementos matemáticos:

A filosofia encontra-se escrita neste grande livro que continuamente se abre perante os nossos olhos (isto é, o universo), que não se pode compreender antes de entender a língua e conhecer os caracteres com que está escrito. Ele está escrito em língua matemática, os caracteres são triângulos, circunferências, e outras figuras geométricas sem cujos meios é impossível entender humanamente as palavras; sem eles nós vagamos perdidos dentro de um obscuro labirinto (GALILEU, 1973, p. 119).

Pode ser dito que em Galileu, a aplicabilidade universal da matemática é enaltecida em detrimento do recurso à autoridade, traço inequívoco do pensamento medieval. Confrontando grande parte dos doutos da Igreja, Galileu explicitou sua hostilidade a Aristóteles, e por conseqüência, à Escolástica, no seu clássico e polêmico livro de 1632, intitulado Diálogo sobre os dois máximos sistemas de mundo ptolemaico e copernicano. Num trecho desta obra, ele escreveu referindo-se a Aristóteles: 
Sinto por ele a mesma compaixão que por aquele senhor que, durante muito tempo, com enorme despesa, com o emprego de centenas e centenas de artífices, construiu um suntuoso palácio, mas o vê depois, por ter sido mal alicerçado, ameaçado de desmoronamento; e para não ver com tanta aflição desfeitas as paredes adornadas de belas pinturas, caídas as colunas que sustentavam majestosas varandas, destruídos os forros dourados, arruinados os marcos, as fachadas e os frisos marmóreos construídos com tanto dispêndio, tenta com correntes, troncos, reforços e arcos de ferro salvar tudo da ruína (GALILEU, 2000, p. 136)

A matemática, para parte dos autores desta época, incluindo obviamente Galileu, acabou transformando-se em um instrumento límpido, neutro, através do qual os fenômenos podiam ser demonstrados sem que alguma teoria previamente estabelecida necessariamente tivesse que ser confirmada. Esta mesma tendência, cabe dizer, se manifestou em Varenius.

A imagem tradicional de universo também sofreu modificações através da ciência galileana. Através do telescópio, o italiano viu novas maravilhas nos céus. Através da visão das manchas solares e do relevo lunar, a divisão aristotélica entre mundo sublunar corruptível e mundo lunar incorruptível caiu por Terra. Havia assim corrupção e transformação nos céus. Varenius escreveu sobre isso, como veremos, em sua Geografia Geral.

Os instrumentos científicos, para Galileu, deveriam corrigir as ditas autoridades (...) ora nós, graças ao telescópio, aproximamo-lo (o céu) trinta ou quarenta vezes mais do que o era para Aristóteles, tal que podemos discernir nele coisas que ele não podia ver (2000, p. 137).

No âmbito filosófico, Francis Bacon (1561-1626) e René Descartes (1596-1650) propiciaram muitos dos princípios e máximas que formaram a especificidade da visão científica de mundo. Além de grandes contribuições de cunho metodológico - vide as obras Novum Organum e Discurso sobre o método -, contribuíram para a reformulação da imagem de homem, de natureza e de sociedade tendo como princípio basilar a aplicabilidade dos postulados científicos em todas as esferas da vida.

Atacando diretamente o dualismo teoria-prática, homo sapiens-homo faber, F. Bacon argumentou que uma teoria só pode ser considerada verdadeira 
quando gerar um benefício prático à sociedade, explicitado, por exemplo, na elaboração de uma técnica de intervenção humana sobre o meio físico. Nesta perspectiva, tipificou enquanto inócuas as contribuições dos gregos - exceção feita a alguns pré-socráticos,--, dos escolásticos e dos alquimistas do seu tempo, ainda que estes tenham auxiliado no desenvolvimento do método experimental. Rossi (2006) salienta que F. Bacon criticou, neste sentido, as filosofias que contrapõem arte - artifício humano - e natureza, uma vez que esta distinção, para F. Bacon, teria tirado do homem a real possibilidade de transformação da natureza e, também, da vida humana. No Novum Organum, Francis Bacon conclama para que (...) o gênero humano recupere os seus direitos sobre a natureza, direitos que the competem por dotação divina (BACON, 1999, p.98). Ciência e utilidade coincidiriam nas obras do chanceler inglês. Veremos, mais tarde, que este mesmo vínculo aparecerá na obra de Varenius.

No clássico Discurso do método, Descartes (1999) ressalta a necessidade de criação de um método que regre o espírito humano. Nessa perspectiva, Descartes auferiu regras, procedimentos para a boa condução do pensamento, elemento imanente e delimitador da essencialidade humana.

Neste sentido, o pensador francês considerou necessária a negação de parte do legado cultural acumulado até então, mantendo o tom de ruptura presente no pensamento baconiano: fugir dos preceptores e do saber livresco; negar a álgebra de seu tempo; considerar apenas do ponto de vista histórico as filosofias de Platão e de Aristóteles, fugir dos equívocos da infância, fase em que os sentidos estariam à frente da razão. Estes são alguns dos preceitos cartesianos para o aprimoramento da razão.

Cabe ressaltar a notoriedade atingida pelo cartesianismo que, em lugares como os Países Baixos, foi concebido como sinônimo de cientificidade. O matematismo e a perspectiva mecanicista foram características inequívocas desta filosofia, talvez a mais influente em se tratando da Geografia Geral de Varenius.

$\mathrm{Na}$ física cartesiana, conhecida por física dos turbilhões, a natureza aparecia como uma totalidade encadeada por diversos nexos de causa e efeito, que perpetuariam uma regularidade mecânica ao mundo cujo 
movimento se daria através de diferentes níveis de contato entre os elementos. No texto clássico em que os princípios desta física são apresentados, Descartes (2008) ressaltou, argumentando contra a existência do vazio:

(...) todos os movimentos que são realizados no mundo são de algum modo circulares, isto é, quando um corpo deixa seu lugar, ele entra sempre no lugar de um outro e esse outro em um deixado por outro e assim ocorre até o último, que ocupa o lugar deixado pelo primeiro corpo. Desse modo não há vazio entre esses corpos: nem quando eles removem-se, nem quando estão parados (p.37).

Declínio do Geocentrismo e da posição privilegiada do homem no cosmo. Sugestão de infinitos mundos num universo obviamente descentralizado. Decadência da hegemonia simétrica do círculo. Relativização da sapiência dos antigos. Matematização da experiência insuflando a ideia de experimentação. Posse da natureza mediante a potencialização da técnica pela ciência. Mecanização do mundo. Eis alguns dos temas e transformações no plano da cultura ocidental que estimulavam a reflexão de boa parte dos intelectuais nos tempos de Varenius. Quase que simultaneamente a estas transformações, alterava-se, profundamente também, a imagem que nutríamos de planeta graças a experiência dos chamados Descobrimentos Marítimos.

\subsection{Os Descobrimentos Marítimos e o desvelamento da Terra}

A época de Varenius, caracterizada pela ampla abertura de mundo propiciada pelos Descobrimentos, gerou condições bastante favoráveis para o acúmulo de novas informações, o que acarretou tanto uma renovação de conteúdo quanto uma renovação de método no que se refere ao saber geográfico. Assim, existiram condições concretas para a superação, do ponto de vista científico, do saber produzido na Idade Média.

Podemos, ainda que brevemente, tipificar o conhecimento geográfico produzido ao longo da Idade Média como um saber gerado a partir da prática de transcrição e reorganização da palavra escrita, o que nos conduz a afirmar a existência de um pequeno peso atribuído à experiência, no sentido moderno do 
termo. É o caso, por exemplo, de Isidoro de Sevilha (600-636) que, no ambiente da Alta Idade Média, escreveu Etymologiae, obra composta por vinte livros. Nesta obra, Isidoro de Sevilha descreveu os habitantes da Etiópia, de acordo com Kimble (2000), com as mesmas palavras que Solinus havia usado para descrever os indianos. Aqui, além da deturpação, há o problema da própria veracidade do texto de Solinus, amplamente escrito tendo por base este mesmo procedimento de cópia/transcrição. Neste caso, este procedimento foi feito em relação à História Natural, de Plínio, o Velho.

Jean de Mandeville (século XIV), autor muito referenciado por navegantes do século XV e até do XVI, manteve essa tendência, já no final da Idade Média, de construir uma narrativa geográfica com base na transcrição e reorganização da palavra escrita. Assim como Isidoro de Sevilha e Solinus, Jean de Mandeville copiou e refundiu diálogos de outros viajantes, trabalhando com informações de enciclopédias e tratados de História e Geografia. Acosta (1993) ressalta que o seu Tratado das coisas mais maravilhosas e notáveis que existem no mundo, publicado no Brasil como Viagens de Jean de Mandeville, foi uma síntese de tratados anteriores do mesmo tipo. O texto chama a atenção para a elegante escrita e pelo tom aventuresco oriundo da narrativa desenvolvida na primeira pessoa do singular, feita com o intuito de conduzir o leitor a crer numa suposta experiência pessoal de seu autor. O trecho relativo á travessia do Vale Perigoso foi claramente copiado da narrativa de viagem do franciscano Odorico de Pordenone (1265-1331) .

Podemos concluir, portanto, como faz Kimble (2000) que, mesmo com os avanços gerados pela navegação no Mediterrâneo e com a irrupção de uma nova intelectualidade a partir do séc. XII, a Geografia do século XV, quando

\footnotetext{
${ }^{6}$ Um dos trechos da passagem claramente transcrita por Jean de Mandeville, referente ao dito Vale Perigoso, é o seguinte: Mas quando entrava por ele, como já disse, vi tantos corpos mortos que, se alguém não os visse, Ihe pareceria quase incrível. No mesmo vale, num dos seus lados, na pedra da parede, vi a face de um homem muito terrível; era tão terrível que, pelo grande medo, pensei que iria perder os sentidos ou que pereceria. (...) Todavia, não ousando aproximar-me dali, fui à outra ponta do vale. E, então, subi um monte de areia (...). Quando cheguei ao cume do monte, encontrei grandíssima quantidade de ouro e prata, ali reunida (...) (PORDENONE, 2005, p. 334). Na obra de Jean de Mandeville encontramos a seguinte narrativa: Esse vale está, e sempre esteve, cheio de demônios. A gente diz que é uma das entradas do inferno. Nele, há muito ouro e muita prata (...). No centro desse vale, sob uma rocha, há uma cabeça com cara de demônio, terrificante e horrível à vista, só podendo ser vista até os ombros. (...) Fiquei assombrado com a existência de tantos mortos e com o de que seus corpos estavam inteiros e sem se decomporem (MANDEVILLE, 2007, pp. 235-6).
} 
Colombo chegou à América, não era muito diferente, em termos informações compiladas, daquela dos primeiros séculos da Idade Média. Houve, portanto, a manutenção do modelo textual de compreensão do mundo, aqui exemplificado pelas obras de Isidoro de Sevilha e Jean de Mandeville.

A permanência de uma tradição textual pouco afeita ao contrapeso de evidência empírica pode ser encontrada no primeiro texto escrito por um europeu sobre o continente americano. Cristóvão Colombo, em seus diários de viagem, recriou parte dos dogmas geográficos antigos e medievais. Ressaltou que Aristóteles teria mencionado a pequenez do mundo, sendo escassa a água e, portanto, fácil a locomoção da Espanha para a Índia. Plínio, autor modelo para as crônicas medievais, dada a magnitude do Império Romano, supostamente saberia tudo o que era permitido saber sobre a configuração do mundo. Isidoro de Sevilha e Santo Ambrósio foram citados em alusão à existência do Paraíso no Extremo Oriente (COLOMBO, 1991), onde achava ter chegado em $1492^{7}$.

O almirante genovês pouco se apercebeu de sua chegada em um novo continente. Um ano após a sua morte, em 1507, irromperia pela primeira vez na história da Cartografia o continente americano em uma representação do mundo. O planisfério anônimo, atribuído a Martin Waldseemüller (1470-1522), que teria sido responsável pelo batismo do Novo Mundo, como ressalta Boorstin (1989), conta em sua parte superior com Ptolomeu olhando para o leste e com Vespúcio, lançando a vista para oeste. Alargou-se agora, de fato, o horizonte da percepção humana do mundo.

Os chamados Descobrimentos Marítimos foram, aos poucos, redimensionando a dimensão e a magnitude da imagem de mundo proveniente da tradição europeia. Em setembro de 1522, por exemplo, o navio Victoria aportou em águas espanholas, tendo a bordo dezoito homens famintos e esfarrapados. Entre eles estava Antonio Pigafetta (1491?-1534), autor do diário da viagem comandada por Fernão de Magalhães que, junto com outros

\footnotetext{
${ }^{7}$ Alexander von Humboldt (1950), em seu clássico Quadros da Natureza, fez alusão à expectativa de Colombo de ter chegado às imediações do Paraíso. Assim, ressalta que o almirante (...) viu no Orenoco um dos quatro rios, que, segundo as veneráveis tradições espalhadas desde a infância do mundo, nasciam no paraíso para regar e dividir a terra, adornada de flores sempre desabrochadas (HUMBOLDT, 1950, p.214)
} 
218 homens, faleceu em meio à jornada. Graças a esta jornada, conhecida como a primeira viagem ao redor do mundo, soube-se, pela primeira vez, das reais dimensões do Oceano Pacífico ${ }^{8}$, o que viria a modificar o argumento ptolemaico de um planeta constituído em sua maioria por terra firme, além de sugerir uma até então pouco concebida comunicabilidade entre os oceanos.

Nesta e em outras viagens do chamado período dos Descobrimentos Marítimos, surgiu, aos poucos, uma clara ânsia por um saber realista que vinculasse a soberania dos dados empíricos com as necessidades econômicas de uma Europa mercantilista. Não é por acaso que o Thetrum Orbis Terrarum (A representação do mundo), de Abraham Ortelius (1527-1598), publicado em maio de 1570, obteve êxito comercial imediato, logo surgindo traduções para 0 holandês, alemão, francês, espanhol, italiano e inglês. Os 53 mapas deste verdadeiro precursor dos Atlas modernos apresentam um mundo renovado em sua aparência graças ao esforço cooperativo, como destaca Boorstin (1989), dos 87 autores que colaboraram para a sua organização. Cabe salientar que Ortelius prosperou no mercado de mapas graças a encomendas de comerciantes.

Varenius, na sua Geografia Geral, demonstrou compartilhar deste espírito tipicamente moderno que associava dados exatos sobre o mundo e êxito comercial.

\begin{abstract}
¿No se debe ello, en gran parte, a conocer las regiones a las que hay que enviar las mercancías, desde las que hay que trasladar hasta allí o hacia otros lugares, su situación, la distancia, los mares que hay en medio, el camino, los lugares vecinos, sí tiene habitantes amigos o enemigos y otros datos que son sacados de los mapas geográficos sin legítimo placer del ánimo? (VARENIO, 1984, p. 89-90).
\end{abstract}

Parte do referencial empírico de que se valeu Varenius para atualizar a imagem do mundo em que os homens de sua época viviam provém dos resultados práticos suscitados pelos chamados Descobrimentos Marítimos.

\footnotetext{
${ }^{8}$ Pigafetta (2005) no aludido diário de viagem, relata o "batismo" das águas descobertas após o cruzamento do hoje Estreito de Magalhães: Chamamos este mar de Pacífico, porque, durante três meses e vinte dias que gastamos na travessia de cerca de quatro mil léguas, não houve a menor tempestade (p.82).
} 


\section{A estrutura da Geografia Geral}

No corpo de sua obra de 1650, Varenius dividiu a Geografia em duas partes: uma Geral e outra Especial. Nas palavras de Varenius (1984), Geografia General o Universal es llamada la que considera la Tierra en conjunto y explica sus propriedades sin tener em cuenta las particularidades de cada región (p.134). A Geografia Especial ou Particular é a que se deteria na constituição de cada uma das regiões, possuindo, para tanto, dois ramos: a corografia, que descreveria regiões de extensões maiores e a topografia, que deveria descrever com detalhes um lugar ou pequenas extensões do planeta.

O exame articulado entre aspectos gerais e especiais da Terra possibilitaria à Geografia cumprir seu objetivo de compreender tanto a superfície do planeta quanto a composição de suas partes.

Em relação à Geografia Geral, objeto central do texto homônimo de 1650, Varenius a divide em três momentos, que correspondem aos três livros que compõem a obra aqui em questão: Parte Absoluta, Parte Relativa e Parte Comparativa.

O Livro I, composto assim pela Parte Absoluta, tem por objeto o que Varenius (1984) chama de (...) la masa misma de la Tierra y sus partes $y$ propriedades, como la forma, el tamaño, el movimiento, las extensiones de terra, los ríos, etc (p.135).

. O referido livro se orienta, como pode ser percebido no Quadro I, para um nível cada vez mais detalhado de compreensão dos elementos que compõem a Terra. Há, neste sentido, a preocupação em se precisar conceitualmente aspectos empíricos que, enredados, atuam na composição da superfície do planeta: de montes a jazidas, de lagos a lagunas, de pântanos a rios, Varenius classifica, ordena e divide, sempre à maneira do analitismo cartesiano, os elementos que compõem a grafia do mundo.

Assim, ordenando a variedade da existência, inventariada no sentido de aplicação de palavras verdadeiramente condizentes com cada singular fenômeno abordado a partir da experiência, o aporte de Varenius percorreria o espaço passo a passo, distanciando-se, nestes termos, do aspecto livresco e dependente das autoridades que caracterizou a produção do conhecimento 
geográfico ao longo da Idade Média. Usando um raciocínio que Durant (2000) aplicou ao advento do cartesianismo, não seria de todo exagerado dizer que o teor analítico de Varenius trouxe, para o âmbito geográfico, a hemorragia do símbolo ressaltada por Durant em alusão a Descartes, uma vez que o autor da Geografia Geral, afastando-se de todo e qualquer resquício teológico, lançou mão de um realismo que rompeu o laço entre significante e significado que tipificava o simbolismo religioso medieval expresso, por exemplo, nos mapas repletos de temas religiosos. Na Idade Média, tal laço tornava o empírico mera marca de um significado de conotação espiritual e moral supraterrena, o que conduzia à relativização da experiência no sentido moderno do termo.

No livro II, intitulado Parte Relativa, Varenius ressalta a utilidade de se construir um globo terrestre visando simular a incidência da luz solar diária sobre as diferentes partes do planeta. É neste sentido que Varenius (1984) destaca a consideração de las propiedades y accidentes de la Tierra debidos a causas celestes (p. 135).

Assim, os fenômenos abordados aparecem relacionados ${ }^{9}$ com preceitos astronômicos que permitem o estabelecimento de relações entre outros astros e a natureza do nosso planeta. São descritos aspectos, evidenciados no Quadro I, como: a latitude dos lugares e a elevação ao pólo; as zonas climáticas e as relações com os fenômenos celestes; a duração distinta dos dias em diferentes lugares e, a partir disso, a distinção da Terra da superfície em diferentes climas; enumeração das causas que podem provocar ou variar a luz, o calor, etc.; a comparação das propriedades celestes nos diversos lugares; a comparação dos habitantes em um mesmo paralelo; o nascimento e ocaso do sol e dos outros astros em diferentes lugares, entre outros.

O Livro III, intitulado Parte Comparativa Terrestre visa, por sua vez, explicar diferentes propriedades terrestres deduzidas da comparação realizada entre distintos lugares do planeta. Nestes termos, são estudados temas como: sobre a longitude dos lugares (dadas as horas de dois lugares em um mesmo

\footnotetext{
${ }^{9}$ Cabe ressaltar que na obra Cosmos, Alexander von Humboldt ressalta que o nosso planeta não pode ser compreendido sem uma conexão cósmica, uma vez a que a própria palavra planeta desperta a ideia de uma dependência com relação a um corpo central e de uma relação com um grupo de corpos celestes diferentes que, provavelmente, teriam tido uma mesma origem (HUMBOLDT, 1949).
} 
instante de tempo, achar a longitude de um lugar com relação a outro; tabela de longitude e latitude dos lugares mais conhecidos, etc.); sobre a situação respectiva dos lugares, sobre a composição do globo terráqueo e sobre os mapas (dado um lugar da Terra, achar e referir a ela a situação dos demais lugares, etc.); da distância dos lugares (dados dois lugares na superfície de um globo, traçar neles um perímetro máximo ou um arco que é a distância mais curta entre ambos lugares; achar a distância entre dois lugares de um globo sobre os mapas; dada a longitude e a latitude de lugares, achar suas distâncias, etc.); Sobre o horizonte visível; Sobre a arte de navegar em geral e, em especial, sobre a estrutura dos barcos; sobre a carga dos barcos, entre outros aspectos, que podem ser vistos no já aludido Quadro I.

Quanto à Geografia Especial, Capel (1984) ressalta que ela seria uma continuação lógica da Geografia Geral, uma vez que a segunda, antes de tudo, constituiria o método que o autor alemão pensava que deveria aplicar em estudos específicos. Assim, os distintos aspectos estudados na Geografia Geral, abordados na obra homônima de 1650, seriam aplicados em cada uma das regiões que seriam objeto da Geografia Especial. Podemos concluir, amparados em Capel (1984), que a morte prematura do autor impediu a sua possível trajetória intelectual rumo à publicação de uma Geografia Especial, que, como ele próprio ressalta, ao lado doas propriedades terrestres e celestes, desenvolvidas ao longo da Geografia Geral, daria primazia aos fatores humanos. Estes foram esboçados por Varenius em número de dez: 1- Estatura dos habitantes, vida, alimento e bebida, origem, etc; 2- Trabalhos e técnicas, mercadorias e preços; 3- Virtudes e vícios, inteligência, conhecimentos; 4Costumes infantis, o matrimônio, a morte; 5- Forma de expressão e língua; 6 Regime Político; 7- Religião e situação da Igreja; 8- Cidades; 9- Feitos famosos; 10- Homens ou mulheres ilustres, artistas, inventos.

Por mais que Varenius tenha afirmado que os fatores humanos pertencem como menor rigor à Geografia, o que é plenamente compreensível dada a restrição dos procedimentos científicos em sua época à Física e à Astronomia (e a adesão de Varenius a eles), é evidente que eles completariam as informações que permitiram à Geografia traçar um quadro completo e 
atualizado do que Varenius (1984) concebeu como objeto de estudos da Geografia: (...) la Tierra, principalmente su superfície y sus partes (p.135).

\section{Quadro I- Estrutura da Geografia Geral}

\begin{tabular}{|c|c|c|}
\hline LIVRO I - PARTE ABSOLUTA & $\begin{array}{c}\text { LIVRO II - PARTE RELATIVA: } \\
\text { acerca das propriedades celestes } \\
\text { e da Terra }\end{array}$ & $\begin{array}{c}\text { LIVRO III: PARTE COMPARATIVA } \\
\text { TERRESTRE }\end{array}$ \\
\hline $\begin{array}{l}\text { Cap. } 1 \text { - Sobre os conhecimentos } \\
\text { gerais prévios de Geografia }\end{array}$ & $\begin{array}{l}\text { Cap. } 22 \text { - Definição e conhecimentos } \\
\text { prévios necessários }\end{array}$ & $\begin{array}{l}\text { Cap. } 31 \text { - Sobre a longitude dos } \\
\text { lugares. }\end{array}$ \\
\hline $\begin{array}{lll}\text { Cap. } 2 & - & \text { Conhecimentos } \\
\text { Geométricos prévios }\end{array}$ & $\begin{array}{l}\text { Cap. } 23 \text { - Sobre a latitude dos } \\
\text { lugares e a elevação do Pólo }\end{array}$ & $\begin{array}{l}\text { Cap. } 32- \\
\text { respectiva dos lugares, sobre a } \\
\text { composição do globo terráqueo e } \\
\text { sobre os mapas. }\end{array}$ \\
\hline Cap. 3 - Sobre a forma da Terra & $\begin{array}{l}\text { Cap. } 24 \text { - Sobre as Zonas e os } \\
\text { fenômenos celestes nas diferentes } \\
\text { Zonas }\end{array}$ & Cap. 33 - Da distância dos lugares. \\
\hline $\begin{array}{l}\text { Cap. } 4 \text { - Sobre a medida e a } \\
\text { superfície da Terra }\end{array}$ & $\begin{array}{l}\text { Cap. } 25 \text { - Sobre a duração distinta } \\
\text { dos dias em diferentes lugares e, a } \\
\text { partir daí, a divisão da superfície em } \\
\text { climas }\end{array}$ & Cap. 34 - Sobre o horizonte visível. \\
\hline $\begin{array}{l}\text { Cap. } 5 \text { - Sobre o movimento da } \\
\text { Terra }\end{array}$ & $\begin{array}{l}\text { Cap. } 26 \text { - Acerca da luz, do calor, do } \\
\text { frio e das estações do ano em } \\
\text { diferentes lugares e Zonas da Terra }\end{array}$ & $\begin{array}{l}\text { Cap. } 35 \text { - Sobre a arte de navegar } \\
\text { em geral e, em especial sobre a } \\
\text { estrutura dos barcos. }\end{array}$ \\
\hline $\begin{array}{l}\text { Cap. } 6 \text { - Sobre o lugar da Terra no } \\
\text { sistema do universo }\end{array}$ & $\begin{array}{l}\text { Cap. } 27 \text { - Sobre as sombras e a } \\
\text { denominação surgida dos lugares a } \\
\text { partir daí }\end{array}$ & Cap. 36 - Sobre a carga dos barcos. \\
\hline $\begin{array}{l}\text { Cap.7 - Sobre a substância e } \\
\text { constituição da Terra }\end{array}$ & $\begin{array}{l}\text { Cap. } 28 \text { - Sobre a comparação das } \\
\text { propriedades celestes nos diversos } \\
\text { lugares e sobre a denominação } \\
\text { surgida daí, das pessoas que vivem } \\
\text { em um mesmo meridiano, à mesma } \\
\text { distância do equador, mas em } \\
\text { hemisférios diferentes. }\end{array}$ & $\begin{array}{l}\text { Cap. } 37 \text { - A limeneurética ou arte de } \\
\text { dirigir a nave (primeira parte). }\end{array}$ \\
\hline $\begin{array}{l}\text { Cap.8 - Sobre a divisão das partes } \\
\text { da Terra nas partes que a integram a } \\
\text { partir do mar }\end{array}$ & $\begin{array}{l}\text { Cap. } 29 \text { - Sobre a comparação do } \\
\text { tempo em lugares diferentes; }\end{array}$ & $\begin{array}{l}\text { Cap. } 38 \text { - Segunda parte da arte de } \\
\text { navegar. }\end{array}$ \\
\hline $\begin{array}{l}\text { Cap. } 9 \text { - Sobre os montes em geral e } \\
\text { sobre a medida da altitude }\end{array}$ & $\begin{array}{l}\text { Cap. } 30 \text { - Sobre os diferentes raios } \\
\text { do Sol, da Lua, etc, e também outros } \\
\text { aspectos.. }\end{array}$ & $\begin{array}{l}\text { Cap. } 39 \text { - A histiodromía ou linha de } \\
\text { rumo da nave. }\end{array}$ \\
\hline $\begin{array}{l}\text { Cap. } 10-\text { Sobre os diferentes } \\
\text { montes, etc. }\end{array}$ & & $\begin{array}{l}\text { Cap. } 40 \text { - sobre o conhecimento do } \\
\text { lugar em que chega a nave em } \\
\text { qualquer momento da navegação e } \\
\text { sua sinalização dos mapas }\end{array}$ \\
\hline \multicolumn{3}{|l|}{ Cap. 11 - Jazidas, selvas e desertos } \\
\hline \multicolumn{3}{|l|}{$\begin{array}{l}\text { Cap. } 12 \text { - Sobre a distribuição do } \\
\text { Oceano nas terras }\end{array}$} \\
\hline \multicolumn{3}{|l|}{$\begin{array}{l}\text { Cap. } 13-\text { Acerca de algumas } \\
\text { propriedades do Oceano }\end{array}$} \\
\hline \multicolumn{3}{|l|}{$\begin{array}{l}\text { Cap. } 14 \text { - Sobre os movimentos do } \\
\text { oceano, em especial as marés }\end{array}$} \\
\hline \multicolumn{3}{|l|}{$\begin{array}{l}\text { Cap.15 - Lagos, Lagunas e } \\
\text { Pântanos }\end{array}$} \\
\hline \multicolumn{3}{|l|}{ Cap. 16-Acerca dos rios em geral } \\
\hline \multicolumn{3}{|l|}{$\begin{array}{l}\text { Cap. } 17 \text { - Águas minerais, quentes, } \\
\text { ácidas e outras que causam } \\
\text { assombro nas pessoas }\end{array}$} \\
\hline \multicolumn{3}{|l|}{$\begin{array}{l}\text { Cap. } 18-\text { Sobre a mudança e } \\
\text { formação de lugares secos e dos } \\
\text { que possuem água da Terra }\end{array}$} \\
\hline \multicolumn{3}{|l|}{ Cap. 19 - Sobre a atmosfera e o ar } \\
\hline \multicolumn{3}{|l|}{$\begin{array}{l}\text { Cap. } 20 \text { - Sobre o movimento do ar } \\
\text { e dos ventos em geral; sobre as } \\
\text { pragas }\end{array}$} \\
\hline $\begin{array}{l}\text { Cap. } 21 \text { - Sobre os ventos, em } \\
\text { especial, e sobre as tempestades }\end{array}$ & & \\
\hline
\end{tabular}

Fonte: Varenio (1984); Org.: Bauab (2010). 


\title{
4. $O$ conteúdo inovador: Geografia e modernidade
}

Considerar Varenius um dos precursores, na Geografia, de valores tipicamente modernos significa, antes de tudo, perceber que em sua obra alguns dos eventos que constituíram a Modernidade se manifestaram de forma a fazer de sua contribuição algo efetivamente novo.

Talvez seja a partir da Geografia Geral que os novos procedimentos da Ciência, principalmente no que se refere à devoção pela experiência, a preocupação com 0 desvendamento de leis gerais e o cuidado com 0 ordenamento lógico e límpido das ideias, à maneira matemática, tenham-se manifestado mais claramente.

Notadamente, em seu texto, não existe espaço para informações provenientes de fontes suspeitas, ou, em outras palavras, em Varenius aquilo que fora por muito tempo um atrativo para o leitor comum europeu - narrativas fabulosas, seres míticos e monstruosos, lugares exageradamente resplandecentes de ouro - cede espaço para, usando uma feliz ideia de Foucault (1999), palavras que expressam rigorosamente coisas conhecidas pela experiência amplificada pelos valores do saber científico latente. Sobre a presença do fabuloso em matéria de Geografia, Varenius escreveu:

\begin{abstract}
Tanto los griegos como los romanos carecían de descripciones verídicas de las regiones remotas y dejaron innumerables escritos falsos y fabulosos sobre los pueblos situados en los confines de Asia y en los lugares septentrionaales (1984, p.143)
\end{abstract}

Os interesses que moviam a sociedade em que vivia Varenius eram bastante claros. Se a geografia das relações comerciais estava, nos séculos XIV e XV, estreitamente vinculada aos limites da vida desenvolvida na sociedade Medieval, trataram, os chamados Descobrimentos Marítimos, de ampliar a escala de ação burguesa, reinventado, pouco a pouco, a percepção do mundo. Este é, pouco a pouco, agigantado, alargado, percebido enquanto orbe. Nesse sentido, a Geografia, para Varenius e, também, para os critérios de validade científica que estavam sendo consolidados, deveria ser, antes de tudo, um conhecimento útil, no sentido mencionado no item anterior em relação à $F$. 
Bacon, às demandas societárias dos novos tempos. Aqui, o conhecimento dos lugares assume uma função primordial, pois dele depende o fluxo comercial crescente insuflado pelas próprias descobertas gradativas de partes da totalidade-mundo. Como já citado anteriormente,

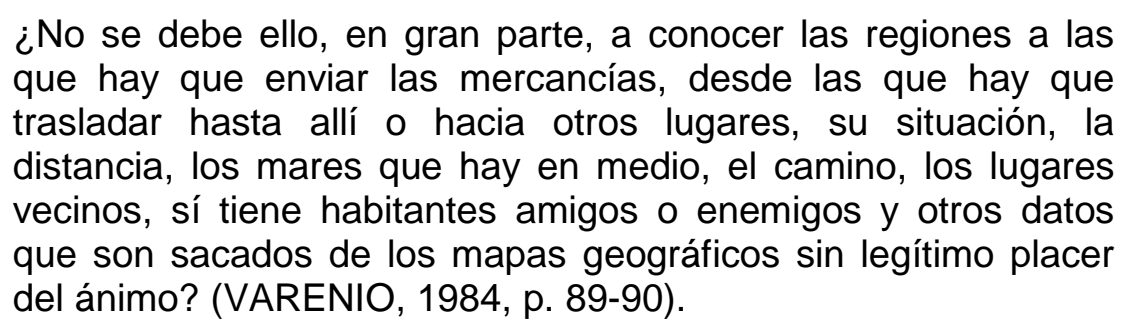

Varenius defende, nas páginas da Geografia Geral, que o conhecimento geográfico ajudaria ao comércio e à marinha, elementos-chave para qualquer governo. Haveria, para o geógrafo, toda uma demanda por um novo saber sobre as partes da Terra e dos oceanos, sobre a situação dos ventos, dos costumes dos povos. Tal demanda, ressalta Varenius, adviria das freqüentes deformidades presentes nos textos de Geografia existentes ainda na efervescente época em que ele vivia.

Sem fazer referência aos autores medievais que se debruçaram sobre temas geográficos, Varenius salta diretamente para a Antiguidade - o que constitui um traço inequivocamente renascentista -, tratando de mostrar a superioridade do seu tempo em matéria de conhecimentos sobre a Terra. Ressalta que os antigos: ignoravam a existência da América e das terras setentrionais; defendiam equivocadamente a o caráter inabitável da zona tórrida, que (...) es habitada por infinito número de pueblos (p.142); desconheciam as verdadeiras dimensões da Terra; ignoravam as propriedades magnéticas da Terra; não puderam saber que (...) África y la parte austral da África puede ser circunnavegada (1984, pp.142-143).

Cabe mencionar a crença comum entre os antigos gregos na existência de um imenso continente austral. Pompônio de Mela, por volta de 43 a.C., representou o aludido continente, que desde Ptolomeu, foi muitas vezes colocado emendado à África, fechando o Oceano Índico. Foram as navegações de Bartolomeu Dias e Vasco da Gama que puseram fim a este fechamento do Índico, conquistando, como ressalta Varenius, a circunavegação da África. Já a 
crença na existência do aludido continente austral foi praticamente desfeita pela segunda viagem de James Cook (1728-1779), ocorrida próxima ao último quartel do século XVIII. Nesta viagem, segundo Boorstin (1989) Cook chegou a estar a $120 \mathrm{Km}$ da Antártida sem ter vistas com o mítico continente.

Percebe-se claramente em Varenius, portanto, um amplo conhecimento dos resultados geográficos oriundos das chamadas "Grandes Navegações". Leu, provavelmente, os jesuítas portugueses, presentes antes dos holandeses, em terras nipônicas. Conhecia, com certeza, as narrativas provenientes das viagens holandesas do começo do século XVII. Uma delas, inclusive, como destaca Capel (1984), teria contado com dois navios enviados por um tal Cornelis Schouten que, em 1616, "dobrariam" o extremo sul da América, desembarcando posteriormente nas Índias Orientais, perfazendo o caminho originalmente traçado por Fernão de Magalhães no início do século XVI.

Podemos concluir parcialmente que, parte da modernidade inerente à Geografia Geral de Varenius, provém das informações geradas pelos ditos Descobrimentos.

Cabe mencionar que autores como Bartholomeu Keckermann (15731609), chegaram a produzir, antes de Varenius, uma Geografia renovada na aparência e nas informações, ao mesmo tempo em que demonstraram a permanência de reminiscências teológicas/escolásticas. É o caso, também, do jesuíta francês Philip Briet e de sua Parallella Geographiae, de 1648.

José de Acosta (1540-1600), por sua vez, em sua História Natural e Moral das Índias de 1590 chegou a questionar os ensinamentos aristotélicos, afirmando ser a zona tórrida aprazível e povoada: (...) a región media, que llaman Tórrida, en realidad de verdad la habitan hombres y la hemos habitado mucho tiempo, y es su habitación muy cômoda y muy apacible (ACOSTA, s.d., p.123). Contudo, o padre espanhol mostrou certo pudor em relação às verdades da fé principalmente no que se refere à origem dos índios, em que se remeteu dogmaticamente à proveniência adâmica de todos os homens. Outro aspecto, digamos, tradicional que permanece em Acosta é o geocentrismo. $O$ eminente padre, quando se depara, por exemplo, com o regime dos ventos americanos, defende como primeira causa o movimento do primeiro móvel. É 
importante ressaltar que somente após 32 anos da morte de Acosta é que a questão do heliocentrismo ganharia mais destaque no pensamento europeu graças ao já mencionado texto de Galileu.

Em Varenius, apesar de sua origem protestante, não há qualquer tipo de permanência religiosa, o que o conduziu, por assim dizer, a um conhecimento geográfico modernamente apartado de significações religiosas. Um exemplo disso é a sua aproximação com o heliocentrismo copernicano/galileano.

Para alguns, o debate sobre os sistemas de mundo já aparece logo no frontispício da Geografia Geral (Imagem I).

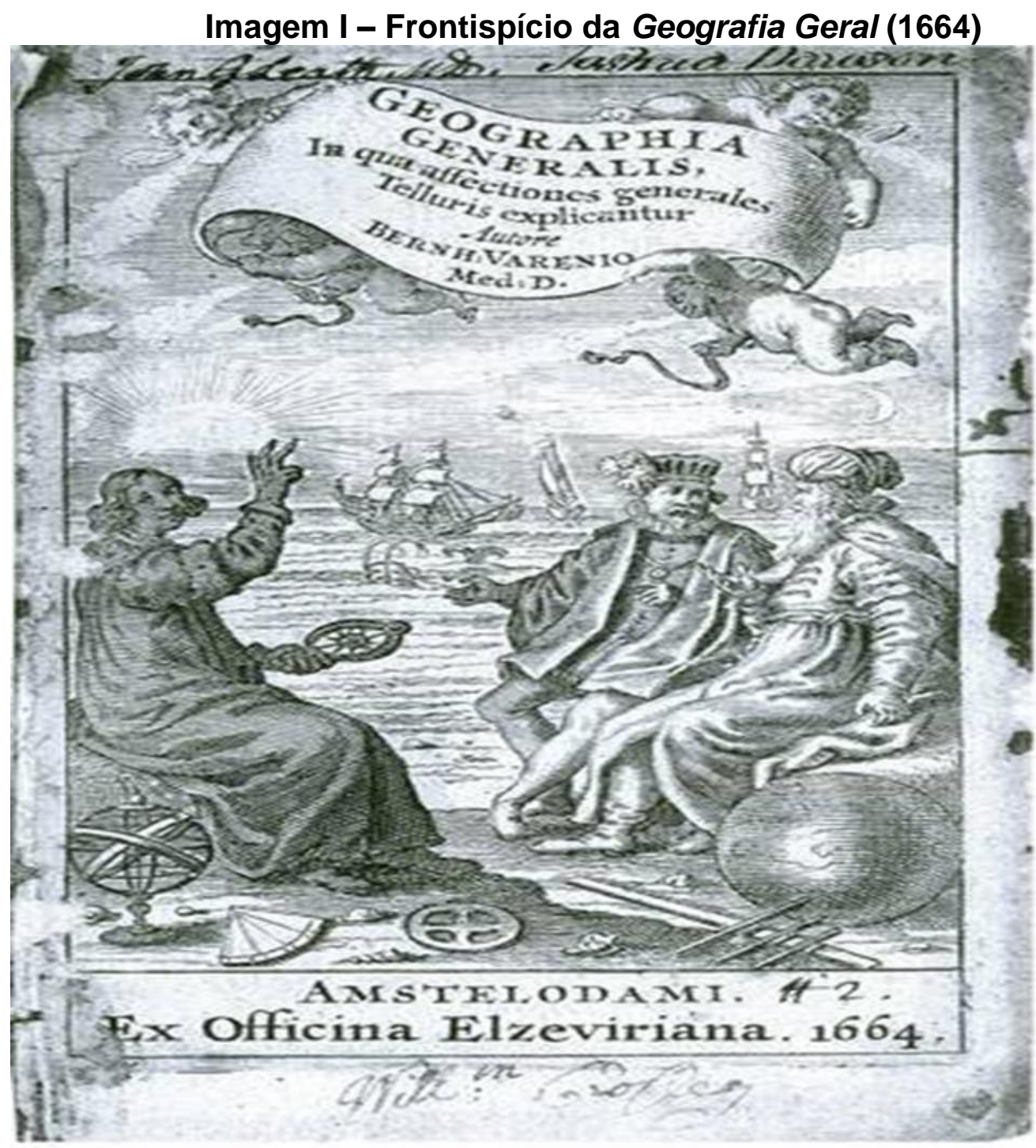

Fonte: http://www.varenius.nl Acesso em: 23/10/2010. 
Antes de explicarmos os supostos significados da imagem, cabe ressaltar que tanto a capa quanto o conteúdo desta edição de 1664, que estamos usando como ilustração, são exatamente iguais ao que foi publicado em 1650.

Lange (apud WARNTS, 1989) ressalta que o homem, à esquerda do frontispício, seria Varenius a dar explicações a dois governantes da cidade de Amsterdã, cercado por globos e outros instrumentos de medições do céu. $\mathrm{Na}$ mão esquerda Varenius, nesta interpretação, empunha um modelo do sistema heliocêntrico. O referido autor identifica que os dois outros homens seriam Banning Cocq, ao centro, e Klaes Corver, à direita. Ambos aparecem nos agradecimentos de Varenius na epístola do seu texto e, como homens de negócios interessados em matéria geográfica, teriam patrocinado os estudos de Varenius.

Por sua vez, Lebed'ev (1950) identificou os indivíduos como sendo Copérnico, Tycho Brahe e Ptolomeu, numa clara alusão aos três sistemas de mundo concebidos no século XVII: o heliocêntrico, o ticônico e o geocêntrico. A atitude professoral de Copérnico, localizado evidentemente à esquerda, poderia, assim, expressar uma defesa da superioridade do seu sistema.

Ainda no que se refere à relação de Varenius com a Ciência Moderna, podemos enfatizar que o autor da Geografia Geral deparou-se com o debate empreendido em seu interior frente a algumas máximas de Aristóteles, recorrente no que podemos chamar de Ciência Medieval

No aristotelismo, por exemplo, há a oposição entre mundos lunar e sublunar. A Terra, situada abaixo das esferas incorruptíveis da lua, do planeta e das estrelas fixas, seria um corpo afeito à corrupção, mudança e degeneração. Acima da Terra, tudo permaneceria sempre igual, com os corpos celestes imutáveis, incorruptíveis, perfeitamente lisos e esféricos. Provinha desta distinção aristotélica aceita como teoria oficial pela Igreja Católica, uma noção de inferioridade atribuída ao nosso planeta, único locus, no Universo, de mudanças, de degenerações.

Habitado por um ser também corrompido pelo pecado, caído desde o fatídico episódio da Queda, seria, o nosso planeta para este "aristotelismo 
cristianizado", ao mesmo tempo, o centro da Criação e, em termos de perfeição, algo um tanto inferior se comparado aos demais corpos celestes. Num caso mais extremo desta tendência de raciocínio, o Papa Inocêncio III, num texto chamado De contemptu mundi ( $O$ desprezo do mundo), radicalmente aponta o homem como ser inferior ao próprio mundo que habita: anda pesquisando ervas e árvores; estas, porém, produzem flores, folhas e frutos, e tu produzes de ti lêndeas, piolhos e vermes; elas lançam de seu interior azeite, vinho e bálsamo, e tu do teu corpo, saliva, excrementos...(PESSANHA, 1994, p. 31).

Nem o mundo, nem o homem aparecem expostos em teores indignos no texto de Varenius. Tal temática, excessivamente religiosa, não é objeto de interesse no texto da Geografia Geral; nele aparece a ideia, defendida com argumentos diferentes tanto em Giordano Bruno, quanto em Kepler, Galileu e Newton, de que tanto na Terra quanto no restante do Universo ocorreriam transformações, fenômenos semelhantes. Sobre tal assunto, assim se manifestou Varenius:

Pues ni los cuerpos celestes están libres de cambios ni alteraciones, como han demostrado las observaciones de los matemáticos del siglo actual y del anterior, ni hasta el momento se ha prosado con argumentos incontestables que la tierra ocupe el centro del cielo (1984, p.88).

Assim, logo no principio da Epístola que abre o texto, Varenius critica a distinção entre Terra e Céu que advém dos antigos, argumentando que ela de modo alguno parece adecuada a las reglas de la lógica ni a la misma naturaleza (1984, p.87). Neste sentido, cremos que não seria precipitado dizer que Varenius compartilhou daquilo que Koyré (2001) considera como característica central da Ciência Moderna, que é a unificação do universo mediante leis válidas igualmente em todos os lugares e mediante as regras da geometría.

Cabe mencionar que, na época de Varenius, a maior fonte de demonstração de que os corpos celestes não estariam isentos de transformações era, com toda certeza, Galileu Galilei. Foi ele que, mediante o uso do telescópio, equiparou a Terra aos demais corpos celestres, 
demonstrando a existência de manchas solares, de formas de relevo na lua, iniciando o processo de unificação das leis do universo que culminaría na síntese newtoniana.

Sobre a centralidade da Terra, Varenius, de acordo com a citação há pouco reproduzida, ressalta a inexistência de argumentos incontestáveis para a sua defesa. O título do primeiro ítem do capítulo $\mathrm{V}$ (Sobre o movimiento da Terra) da Parte Absoluta da Geografia Geral, é emblemático: O movimento da Terra é a causa dos fenômenos celestes segundo os copernicanos. Em outros momentos, o autor em questão faz alusão ao movimento aparente do Sol. Não seria impreciso afirmar que Varenius seja o primeiro geógrafo heliocéntrico da modernidade. $E$ isso não representa pouco.

Varenius partilha do mesmo tronco comum de conhecimento que conduziu Copérnico, Kepler e Galileu, só para citar alguns nomes, à defesa de teorias "polêmicas" e "subversivas" em sua época: a matemática.

Na Geografia Geral, Varenius afirma ser a ciência geográfica um ramo da Matemática Mista, que explica as propriedades da Terra e de suas partes relativas à quantidade, isto é, figura, situação, dimensões, movimentos, fenômenos celestes e outras propriedades similares. Em sua visão, bastante inovadora em diversos sentidos, o raciocínio matemático serviria, eficientemente, para ordenar os elementos gerais constituintes do planeta, tornando límpida e exata a apreensão dos caracteres geográficos, tanto os concernentes aos aspectos regionais - hábitos alimentares, de saúde, aspectos econômicos gerais, organização política - quanto os relativos à sua forma e dimensões

Depois de dividir a Geografia em Geral e Especial ${ }^{10}$, e definir o seu objeto como a superfície terrestre e suas partes, conforme já vimos, Varenius discorre sobre os princípios da Geografia. Assim, o princípio número um, que precede os outros dois ressaltados por ele (as teorías astronómicas e os dados

10 É bastante conhecida a divisão metodológica realizada por Varenius quanto ao conhecimento geográfico. A Geografia, para Varenius, deveria iniciar sua análise debruçando-se sobre aspectos gerais - a Geografia Geral - relativos à forma, dimensões e posição da Terra no Universo. Enunciadas, claramente, as proposições gerais, aí, sim, deveria a Geografia discorrer sobre caracteres locais, formando uma perspectiva que Varenius chamou de Geografia Especial. 
da experiência e das observações nas regiões), são: las proposiciones geométricas, aritméticas y trigonométricas (p.138).

O raciocínio matemático aparece, em Varenius, como elemento que antecede e que deve fundamentar a experiência, fornecendo um fio seguro por onde pode trafegar tranqüilamente o pensamento:

Ah, pero antes de que las reglas con arreglo a las que se ha establecido la práctica fueran desentrañadas de los secretos de la aritmética y demostradas por los matemáticos y enseñado el método adecuado para su ejercicio, sin duda nada había entonces que pudiera realizar estas cosas (VARENIO, 1984, p.91).

Em outra passagem, Varenius, fazendo clara referência a Amsterdã, exalta a aplicação do conhecimento matemático em diferentes ramos do saber e, também, sua potencial contribuição para a vida do homem:

[...] es muy fácil mostrar la relación con la perspectiva y la mecánica estática, la música, la arquitectura, la geodesia y otras ciencias, de igual manera se pone de manifiesto cuántos beneficios producen las matemáticas (o mathesis) para el uso de la vida humana, principalmente para nuestra ciudad (1984, p.92).

Sendo o fundamento comum das contribuições de eminentes nomes que construíram o saber científico nos séculos XVI e XVII - talvez, aqui, uma única exceção possa ser encontrada em Francis Bacon - , a matemática, provavelmente, teve incidência sobre a produção de Varenius através do cartesianismo bastante influente no ambiente acadêmico da época.

Warntz (1989) ressalta que, em Varenius, havia uma entusiasmada aceitação e apreciação da filosofia e ciência cartesianas. Inclusive, para o referido autor, foram o debate escolasticismo versus cartesianismo o elemento de maior inspiração do estudante Varenius. No texto original da Geografia Geral, acrescenta Warntz (1989), aparecem ilustrações tomadas de Descartes, como demonstram, por exemplo, as relativas ao fluxo e refluxo das marés. Varenius, assim, demonstrava lançar mão de esquemas vinculados à então famosa física dos turbilhões de Descartes para explicar, através de poucas leis gerais, os dois movimentos dos oceanos. 
As edições da Geografia Geral organizadas por Isaac Newton e seus seguidores a partir de 1672 - Newton ainda organizaria uma edição do texto em 1681, e, em 1712 e 1733 sairiam outras versões inglesas organizadas por seguidores de Sir Isaac, como James Jurin e Roger Cotes, entre outros demonstram, em nossa opinião, a modernidade inerente ao conteúdo do material. Tal fato fica ainda mais evidente se nos atermos ao debate entre cartesianos e newtonianos que o seu conteúdo suscitou.

Não entrando na especificidade do debate entre física newtoniana e física derivada de Descartes, que permaneceu hegemônica em alguns centros acadêmicos europeus até a publicação dos Principia (1687), podemos ressaltar, amparados em Warntz (1989), que Newton e os newtonianos trataram, desde a edição de 1672, de, sem macular esquemas e conteúdos eminentemente cartesianos, acrescentar idéias vinculadas às descobertas físicas que realizavam. Warntz (1989) ressalta que os esquemas e tabelas acrescentados por Newton, desde a edição de 1672, incluem aspectos referentes à matemática pura (Geometria aplicada à Geografia) e à matemática mista, abrangendo estudos de temas como refração da luz, altitudes, tempo, navegação, cartografia, projeções, entre outros.

Impera, nas edições newtonianas, uma alusão bastante clara ao fato de que a geometria não deveria ser usada somente como um sistema lógico, mas também como instrumento indispensável para a investigação científica e apresentação de resultados. Na edição de 1712, realizada por James Jurin, foram acrescentadas, de acordo com Warntz (1989), quarenta e seis citações de novos e modernos autores de "tendências newtonianas", como Woodward, Huygens, Cassini, Torricelli, entre outros.

Dentro desta sequência de argumentos que temos apresentado com o intuito de explicitar aspectos que evidenciem o tom moderno do clássico texto de Varenius, um último merece destaque. Estamos nos referindo ao utilitarismo que o aludido autor confere ao conhecimento geográfico, algo que obviamente foi feito em consonância com as demandas de seu tempo. 
Rompendo definitivamente com o aspecto alegórico/dogmático presente na construção do conhecimento geográfico na Idade Média, Varenius ressalta que

(...) lo cierto es que todos los varones sensatos están de acuerdo en que el conocimiento de la Tierra no es sólo muy digno del hombre, sino que es necesario tanto en la República de las letras como en cualquier situación de la vida cotidiana (1984, p.89)

Após argumentar acerca da importância, já salientada neste texto, da Geografia para o comércio, Varenius aponta a sua relevância também para a navegação. Esta argumentação sempre aparece em tom de justificativa com relação à utilidade inquestionável deste ramo do saber. Assim,

(...) Los Marinos reconocen el uso muy amplio y hasta como divino de la Geografía, cuando se aprestan a surcar los mares remotos y el enfurecido Océano, confiados en la exactitud de los mapas geográficos y de otras reglas en que la Geografía abunda para el rumbo de la nave (1984, p.90).

Neste mesmo sentido, Varenius escreve sobre a excelência da Geografia, afirmando que a dedicação a tal assunto oferece: 1) dignidade, porque é essencial ao homem habitante da Terra e dotado de razão entre os demais seres animados; 2) algo ameno, um honesto contemplar sobre as regiões da Terra e suas características; 3) grande utilidade e necessidade, pois nem os teólogos, nem os médicos, nem os juristas, nem os historiadores ou demais escritores (...) poden carecer de un conocimiento de Geografía si quieren avanzar un poco en sus investigaciones (1984, p.144).

Num contexto histórico de ampla mobilidade espacial, de criação de uma teia de rotas marítimas cada vez mais globais, Varenius visa claramente reformar e normatizar o conhecimento geográfico com o claro propósito de responder à frequente demanda por exatidão no que concerne às informações relativas ao nosso planeta, oferecendo uma imagem revigorada de mundo. 


\section{Considerações finais}

Varenius foi, de forma inequívoca, o primeiro autor da Geografia a absorver no âmbito teórico-metodológico as inovações que se desprenderam do advento da Ciência Moderna. O interesse de Newton pela Geografia Geral, e a tentativa de inserção de seus postulados científicos em contraposição ao forte conteúdo cartesiano presente no texto, demonstram o nível de absorção de temas recentes presente na obra.

Amparada pelas evidências empíricas dos chamados Descobrimentos Marítimos, fundamentada sob o argumento da superioridade do raciocínio matemático, lançando mão de autores como Copérnico, Galileu Galilei, Descartes, entre outros, e, por fim, trabalhando problemas geográficos com base na física cartesiana e, com isso, convidando o inovador Newton para um fecundo debate, é, a Geografia Geral, de Varenius, uma obra verdadeiramente nova, prenhe de valores modernos que, até então, nunca haviam-se manifestado com tamanho vigor dentro de um texto de Geografia.

Além disso, nunca é tarde para dizer, o referido texto veio a expressar de forma extremamente lúcida uma questão que seria crucial em teóricos do século XX do pensamento geográfico, como Fred Schaffer e Richard Hartshorne, que é a referente à relação entre aspectos idiográficos e nomotéticos em nossa ciência. À maneira de Schaffer, Varenius defendeu que os princípios nomotéticos (gerais, vinculados à elaboração de leis) seriam condição a priori para estudos regionalizados, que ele denominou de especiais. Seria, para Varenius, o desenvolvimento de uma perspectiva nomotética que assentaria a Geografia no cenário das ciências em gestação.

De tudo que foi afirmado até aqui, portanto, cabe concluir que a Geografia Geral constitui-se num manifesto convite à problematização das origens do pensamento geográfico em sua roupagem moderna. 


\section{Referências}

ACOSTA, José de. História Natural y Moral de las Indias.Madri: Dastin, s.d.

ACOSTA, Wladimir. Viajeros y maravillas. Caracas: Monte Avila Editores, 1993. (três tomos)

BACON, Francis. Novum Organum ou verdadeiras indicações acerca da interpretação da natureza. Trad. de José Aluysio Reis de Andrade. São Paulo: Nova Cultural, 1999. (Col. Os Pensadores)

BOORSTIN, Daniel J. Os descobridores - de como o homem procurou conhecer-se a si mesmo e ao mundo. Trad. Fernanda Pinto Rodrigues. Rio de Janeiro: Civilização Brasileira, 1989.

BRUNO, Giordano. Sobre o infinito, o universo e os mundos. Trad. Helda Barraco e Nestor Deola São Paulo: Abril Cultural, 1973. (Col. Os pensadores)

BURTT, Edwin A. As bases metafísicas da ciência moderna. Trad. José Viegas Filho e Orlando Araújo Henriques. Brasília: Ed. Universidade de Brasília, 1991.

CAPEL, Horácio. Geografia Geral: Edición y estúdio introductorio. Barcelona: Ediciones de la Universidad de Barcelona, 1984.

COLOMBO, Cristóvão. Diários da descoberta da América: as quatro viagens e o testamento. Trad. Milton Person. Porto Alegre: L\&PM, 1991. (Col. A visão do Paraíso)

COPÉRNICO, Nicolau. As revoluções dos orbes celestes. Trad. A. Dias Gomes e Gabriel Domingues. Lisboa: Fundação Calouste Gulbenkian, 1984.

DESCARTES, René. Trad. Enrico Corvisieri. O discurso do método. São Paulo: Abril Cultural, 1999 (Col. Os Pensadores).

DESCARTES, René. O mundo ou o Tratado da Luz. São Paulo: Hedra, 2007.

DURANT, Gilbert. A imaginação simbólica. Trad. Carlos Aboim de Brito. Lisboa: Edições 70, 2000.

FOUCAULT, Michel. As palavras e as coisas. 8 ed. São Paulo: Martins Fontes, 1999. (Col. Tópicos)

GALILEU. O Ensaiador. Trad. Helda Barraco. São Paulo: Abril Cultural, 1973. (Col. Os pensadores)

GALILEU. Diálogo sobre os dois máximos sistemas do mundo ptolomaico e copernicano. Trad. Pablo Rubén Mariconda. São Paulo: Discurso Editorial/Fapesp, 2000.

HARTSHORNE, Richard. Propósitos e natureza da Geografia. São Paulo: Edusp/Hucitec, 1978.

HUMBOLDT, Alexander von. Quadros da natureza. Trad. Assis de Carvalho. São Paulo: W.M. Jackson, 1950. 2v 
KIMBLE, G. H. T. A Geografia na Idade Média. Trad. Márcia Siqueira de Carvallho. Londrina: Ed. da UEL, 2000.

KOYRÉ, Alexandre. Do mundo fechado ao universo infinito. Trad. Donaldson M. Garschagen. 3. ed. Rio de Janeiro: Forense Universitária, 2001.

MANDEVILLE, Jean de. Viagens de Jean de Mandeville. São Paulo: Edusc, 2007.

PESSANHA, José Américo Motta. Humanismo e pintura. In: NOVAES, Adauto (Org.).Artepensamento. São Paulo: Companhia das Letras, 1994.

PIGAFETTA, Antonio. A primeira viagem ao redor do mundo. Porto Alegre: L\&PM, 2005.

PORDENONE, Odorico de. Relatório. In: CARPINE, João de Pian Del (et al). Crônicas de viagem: franciscanos no extremo-oriente antes de Marco Polo (1245-1330). Porto Alegre-RS; Bragança Paulista-SP: EDIPUCRS; EDUSF, 2005.

ROSSI, Paolo. Francis Bacon: da magia à ciência. Londrina: Eduel; Curitiba: Ed. Da UFPR, 2006.

SCHAEFER, Fred. O excepcionalismo na Geografia: um estudo metodológico. In: Boletim Carioca de Geografia (Metodologia em Geografia), Rio de Janeiro, 1976, pp. 9-49.

VARENIO, Bernhard. Geografia Geral- en la que se explican las propriedades generales de la tierra. 2.ed. Trad. José Maria Requejo Prieto. Barcelona: Ediciones de la Universidad de Barcelona, 1984.

WARNTZ, William. Newton, the newtonians, and the Geographia Generalis Varenii. Anais of the Association of American Geographers, 79 (2), 1989, pp165-191. 